\title{
Macroscopic analysis of the patella cartilage during total knee replacement
}

\begin{abstract}
Background: Knee osteoarthritis is diagnoses and monitored with radiography. Arthroscopy is considered the most valid method for evaluation of cartilage lesions. The best way for grading, measure and dimension is direct visualisation.
\end{abstract}

\begin{abstract}
Methods: Patelar cartilage lesion was analysed macroscopically during 176 total knee replacement. The grading of cartilage lesion, by direct visualisation, indentified six diferents groups.
\end{abstract}

Results: Patellar articular cartilage was damaged in all 176 cases. There was no evidence of association between grade of arthrosis, gender, side or age. There is an association between tricompartmental arthrosis, varus deformity, obesity and grade of patelar arthrosis.

Conclusion: All classifications systems regarding the femoropatellar cartilage lesions are unrealistic. Important subchondral bone exposure occurred in $77,2 \%$ patelar articular surface.

Keywords: Patella, Femoropatelar joint, Patellar cartilage, Arthroscopy, Radiographic classification, Grading cartilage lesions
Volume II Issue 3 - 2019

\begin{abstract}
Carlos Roberto Schwartsmann, Leandro de Freiras Spinelli, Gabriel Severo da Silva, João Pedro Farina Brunelli, Leonardo Dalla Giacomassa, Leonardo Disconzi Barboza

Orthopaedic Professor, Complexo Hospitalar, Brazil
\end{abstract}

\begin{abstract}
Correspondence: Prof. Dr. Carlos Roberto Schwartsmann, Professor Titular Ortopedia e Traumatologia da Universidade Federal de Ciências Saúde Porto Alegre/RS - Chefe do Serviço de Ortopedia e Traumatologia da Santa Casa de Porto Alegre/ RS - Chefe do Grupo de Quadril do Serviço de Ortopedia e Traumatologia da Santa Casa de Porto Alegre/RS, Brazil, Email schwartsmann@santacasa.tche.br
\end{abstract}

Received: May 17, 2019 | Published: May 22, 2019

\section{Introduction}

Knee osteoarthritis is commonly diagnosed and monitored with radiography. Intra-observer and inter-observer reliability of radiographic classification systems in this pathology are poor to moderate. When assessed arthroscopically, a wide range of interobserver reliability is found. Probably the best way to classify what happens with the patellar cartilage is direct visualisation.

\section{Methods}

During 176 Total Knee Arthroplasties, the articular surface of the patella was analysed macroscopically and the degree of degeneration of the cartilage was graded. The study was prospective and occurred between April 2016 and August 2017. Femoropatellar replacement was not implemented in our cases. Osteophyte resection was achieved for articular surface regularization and anatomical reestablishment. Electrocautery denervation of the patellar edges was performed circumferentilly. ${ }^{1,2}$ The age of the patients ranged from 51 to 97 years with a mean and standard deviation of $70.1 \pm 7.8$ years. In total, 140 patients $(79.5 \%)$ were female and $36(20.5 \%)$ were male. Right and left knees were compromised in the same proportion: 88 cases each. The body mass index (BMI) ranged from 18.4 to $46.2 \mathrm{~kg} / \mathrm{m}^{2}$ with a mean of $30.3 \pm 4.8 \mathrm{~kg} / \mathrm{m}^{2}$. Only $18(10.2 \%)$ patients were considered normal based on BMI (18-24.9 kg/m²). BMI data were: overweight (25-29.9), 73 cases (41.5\%); obese (30-39.9), 57 cases $(32.4 \%)$; and severely obese or worse (IMC $>35), 28$ cases $(15.9 \%)$. To radiographically grade osteoarthritis, we used the Kellgren-Lawrence ${ }^{3}$ scale: Grade III, 10 cases (5.7\%); and Grade IV, 166 cases (94.3\%).

Regarding axial deviation, only 3 cases were considered normoaxis (1.7\%); 40 had genu-valgum (22.7\%) and 133 had genu-varus (75.6\%). Mean varus deviation was $10.2^{\circ} \pm 4.1^{\circ}$. Mean valgus deviation was $16.8^{\circ} \pm 6.8^{\circ}$. The anatomic tibiofemoral angle was determined with the use of the method described by Hsu et al. ${ }^{4}$ Overall, 170 cases had radiographic signs of tricompartmental arthrosis (96.6\%) and there were 6 cases of bicompartmental arthrosis (3.4\%). Transoperative patellar evaluation was obtained after exposure and eversion.
The classification was consensually performed by the surgeon and three assistants. We classified the articular surface in 6 different groups (Group I-VI):
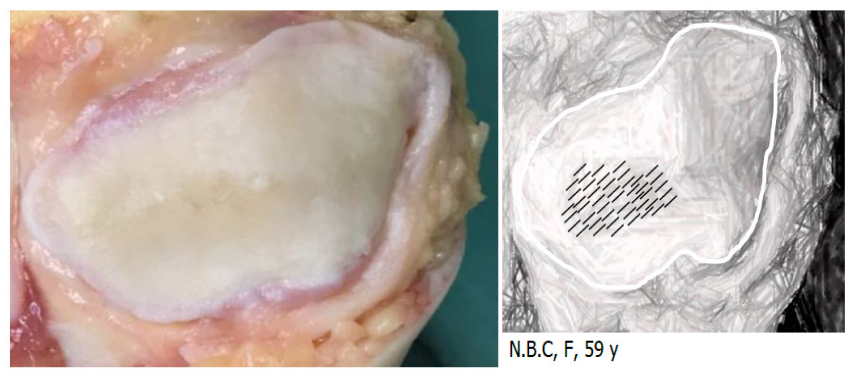

Group I: Signs of softening or fibrillation of the cartilage;

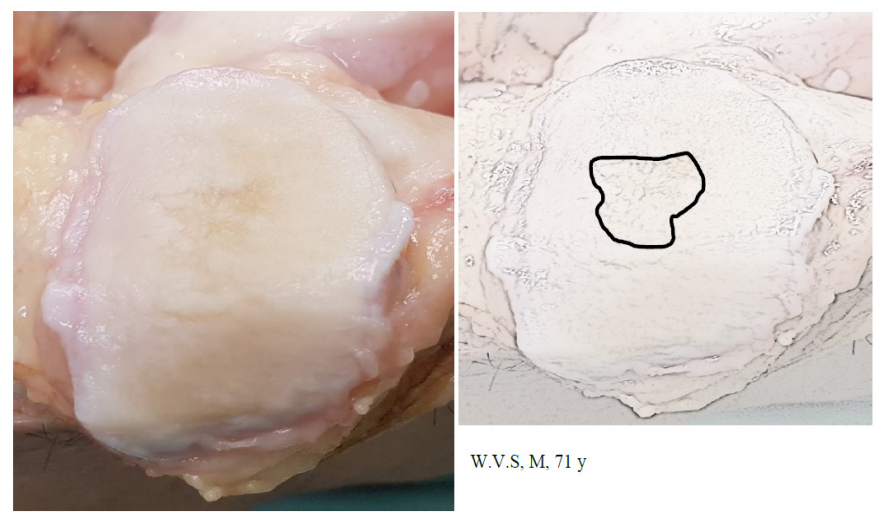

Group II: Fissure and fragmentation of less than $50 \%$ of the diameter of the cartilage; 


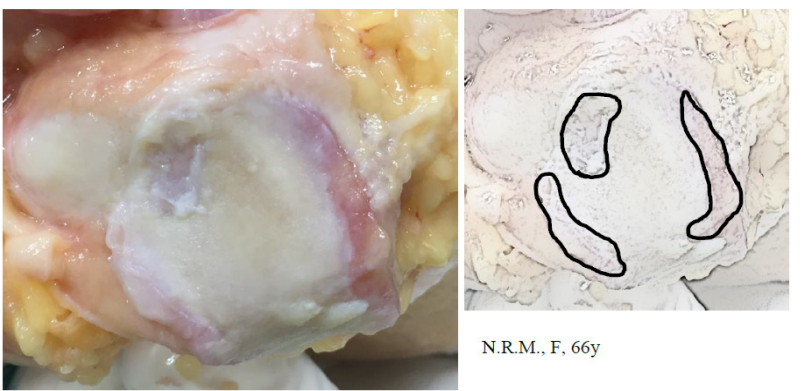

Group III: Erosion exposing the subchondral bone of less than 50\% of the diameter of the cartilage;
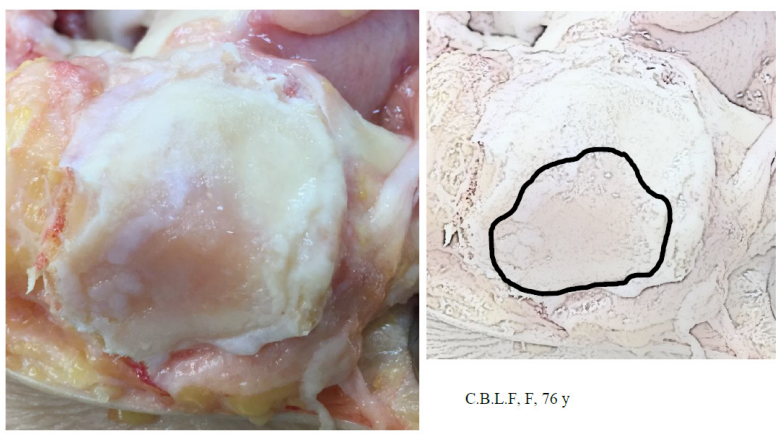

Group IV: Erosion exposing the subchondral bone of more than $50 \%$ of the diameter of the cartilage;

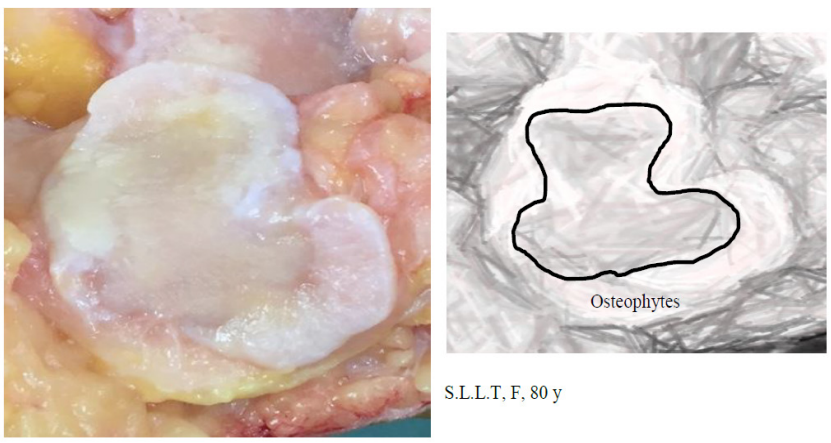

Group V: Erosion of more than 50\% of the cartilage and osteophytes in more than $50 \%$ of the perimeter of the patella;
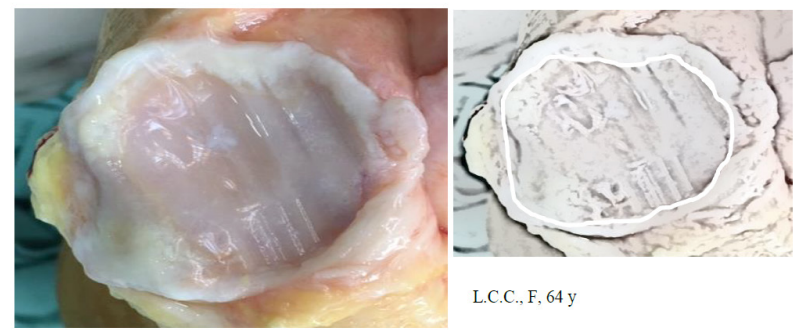

L.C.C., F, 64 y

Group VI: Complete erosion, flattening or inversion of the patellar triangle.

In all cases, some degree of cartilage damage was observed. Only one case was classified as Group I (0.6\%), 18 as Group II (10.2\%),
21 as Group III (11.9\%), 42 as Group IV (23.9\%), 50 as Group V $(28.4 \%)$ and 44 as Group VI $(25.0 \%)$. Combining the three more severe Groups of patients (IV, V and VI - erosion exposing the subchondral bone of more than $50 \%$ of the diameter of the cartilage), we identified 136 patients (77.2\%). Statistical analysis was performed using SPSS (version 21), and Fisher's exact test and Spearman's correlation coefficient were used. This study was approved by the ethics committee of our institution.

\section{Results}

With crossed analysis using Fisher's exact test we concluded:

There was no evidence of association between grade of arthrosis and gender $(\mathrm{P}=0.261)$.

There was no evidence of association between grade of arthrosis and side $(\mathrm{P}=0.264)$.

The sample indicates that there is an association between varus deformity and grade of patellar arthrosis $(\mathrm{P}=0.019)$.

The sample indicates that there is an association between radiographic tricompartmental arthrosis and grade of patellar arthrosis $(\mathrm{P}=0.034)$.

Spearman's correlation coefficient did not show a correlation between age and grade of arthrosis $(\mathrm{P}=0.119)$. However, we found a significant correlation between BMI and grade of arthrosis (0.010), indicating obesity as an important risk factor of patellofemoral arthrosis.

\section{Discussion}

Osteoarthritis of the knee is a disabling disease, resulting in pain, joint discomfort, diminished function and restricted motion. Osteoarthritis is commonly diagnosed and monitored with radiography. Many radiographic classification systems are used in an attempt to confirm articular degenerative cartilage lesion with reliability. For knee osteoarthritis, the most widely used systems are: KellgrenLawrence, ${ }^{3}$ Ahlbäck, ${ }^{5}$ Fairbank, ${ }^{6}$ Brandt, ${ }^{7}$ and the international knee documentation committee (IKDC). ${ }^{8}$ Specifically for the femoropatellar joint, the Iwano ${ }^{9}$ and Merchant ${ }^{10}$ classifications are the most commonly used. All of these classifications had fair to moderate inter-observer and intra-observer reliabilities. ${ }^{11-16}$ However, analysing their correlation with cartilage status assessed arthroscopically, they showed only moderate inter-observer reliability. ${ }^{17-26}$ Many authors agree that radiographic images must be taken in orthostatic and monopodalic weight-bearing. Rosenberg radiographs had a higher correlation with arthroscopic findings of chondral disease than anteroposterior radiographs. ${ }^{27-29}$ Wright and MARS group, correlating osteoarthritis classification with arthroscopic articular cartilage findings, concluded that "IKDC classification assessed with use of $45^{\circ}$ postero-anterior flexion Weight-Bearing radiographs had the most favourable combination of reliability and correlation". ${ }^{30-32}$ Of course, the best way to confirm articular cartilage degeneration is observing directly using arthroscopy.

The most commonly used scale in literature for femoropatellar evaluation is the Outerbridge classification, ${ }^{33}$ but this scale also has a wide range of inter-observer reliability. ${ }^{34-37}$ Cameron, ${ }^{38}$ in a cadaver-based study, concluded: "The Outerbridge classification was moderately accurate when used to grade chondral lesions arthroscopically". Brismar, ${ }^{39}$ in a videotape study, concluded: "The arthroscopic grading of early osteoarthritic lesions is inexact". Razak ${ }^{40}$ 
found a weak correlation between radiographic and arthroscopic findings in Asian osteoarthritic knees. Spahn, ${ }^{41}$ in a multicentre survey with 301 highly experienced arthroscopists, concluded that arthroscopy was not perceived to be as reliable as a "Gold standard" for the diagnosis of cartilage lesions.

The Outerbridge classification is very simplistic and is not a good parameter for deciding whether the patella will be replaced or not in total knee arthroplasty.

Grade 0: is normal articular cartilage,

Grade I: softening of the cartilage,

Grade II: fibrillation or superficial fissures,

Grade III: deep fissuring without exposed bone,

Grade IV: subchondral bone is exposed.

In our study, in all patients we found patellar cartilage lesions. Only $19(10.8 \%)$ patellae were free of subchondral bone exposure (19/176). In $157(89.2 \%)$ cases, the subchondral bone was exposed to different degrees. These findings corresponded to Grade IV in the Outerbridge classification. Exposed subchondral bone of more than $50 \%$ of patellar diameter (Grades IV,V,VI) was found in 136 cases $(77.2 \%)$. All of these correspond to Outerbridge IV. When we considered the worst situation, almost all cartilage disappearance or flattening or inversion of the patellar triangle, we found 44 cases $(25.0 \%)$. This indicates severe osteoarthritis. When analysing the mean age of this group (70.1 years), we recognise it as an elderly group, but we did not find a correlation between age and arthrosis degree $(\mathrm{P}=0.119)$. Another important subject forgotten in the Outerbridge classification is the presence of marginal ostheophytes, especially in early stages. Kijowski et al ${ }^{42}$ correlated the radiographic findings of osteoarthritis and arthroscopic findings of articular cartilage degeneration within the patellofemoral joint. They analysed the sensitivity for the presence of osteophytes, joint-space narrowing, subchondral sclerosis and subchondral cysts. The conclusion was "marginal osteophytes were the most sensitive radiographic feature for the detection of articular cartilage degeneration". Osteoarthritis rarely occurred in the absence of associated osteophyte formation. For this reason, we considered it important to include osteophyte formation in our classification system. With extensively exposed subcondral bone and many osteophytes, more than $50 \%$ of the patellar perimeter, we considered it to be the more severe level (Grade V). In the worst scenario, patellar cartilage disappeared completely (Grade VI).

\section{Conclusion}

Analysing 176 patellar articular surfaces transoperatively in total knee arthroplasty, we concluded:

a. Articular cartilage was damaged in all cases (100\%).

b. Patients with higher BMI had more severe osteoarthritis.

c. Important subchondral bone exposure occurred in $77.2 \%$ of the patients.

d. Probably, until now, all classification systems regarding the femoropatellar joint published in the literature are unrealistic.

\section{References}

1. Keblish PA, Varma AK, Greenwald AS. Patellar resurfacing or retention in total knee arthroplasty. A prospective study of patients with bilateral replacements. J Bone Joint Surg Br. 1994;76(6):930-937.

2. van Jonbergen HP, Scholtes VA, van Kampen A, et al. A randomised, controlled trial of circumpatellar electrocautery in total knee replacement without patellar resurfacing. J Bone Joint Surg Br. 2011;93(8):10541059.

3. Kellgren JH, Lawrence JS. Radiological assessment of osteo-arthrosis. Ann Rheum Dis. 1957;16(4):494-502.

4. Hsu RW, Himeno S, Coventry MB, et al. Normal axial alignment of the lower extremity and load-bearing distribution at the knee. Clin Orthop Relat Res. 1990;(255):215-227.

5. Ahlbäck S. Osteoarthrosis of the knee. A radiographic investigation. Acta Radiol Diagn (Stockh). 1968:Suppl 277:7-72.

6. Fairbank TJ. Knee joint changes after meniscectomy. J Bone Joint Surg Br. 1948;30B(4):664-670.

7. Brandt KD, Fife RS, Braunstein EM, et al. Radiographic grading of the severity of knee osteoarthritis: relation of the Kellgren and Lawrence grade to a grade based on joint space narrowing, and correlation with arthroscopic evidence of articular cartilage degeneration. Arthritis Rheum. 1991;34(11):1381-1386.

8. Hefti F, Müller W, Jakob RP, et al. Evaluation of knee ligament injuries with the IKDC form. Knee Surg Sports Traumatol Arthrosc. 1993;1(34):226-234.

9. Iwano T, Kurosawa H, Tokuyama H, et al. Roentgenographic and clinical findings of patellofemoral osteoarthrosis. With special reference to its relationship to femorotibial osteoarthrosis and etiologic factors. Clin Orthop Relat Res. 1990;(252):190-197.

10. Merchant AC, Mercer RL, Jacobsen RH, et al. Roentgenographic analysis of patellofemoral congruence. J Bone Joint Surg Am. 1974;56(7):13911396.

11. Petersson IF, Boegård T, Saxne T, et al. Radiographic osteoarthritis of the knee classified by the Ahlbäck and Kellgren \& Lawrence systems for the tibiofemoral joint in people aged 35-54 years with chronic knee pain. Ann Rheum Dis. 1997;56(8):493-496.

12. Mehta VM, Paxton LW, Fornalski SX, et al. Reliability of the international knee documentation committee radiographic grading system. Am J Sports Med. 2007;35(6):933-395.

13. Schiphof D, Boers M, Bierma-Zeinstra SM. Differences in descriptions of Kellgren and Lawrence grades of knee osteoarthritis. Ann Rheum Dis. 2008;67(7):1034-1036.

14. Cho WJ, Bin SI, Kim JM, et al. Total Knee Arthroplasty With Patellar Retention: The Severity of Patellofemoral Osteoarthritis Did Not Affect the Clinical and Radiographic Outcomes. $J$ Arthroplasty. 2018;33(7):2136-2140.

15. Köse Ö, Acar B, Çay F, et al. Inter- and Intraobserver Reliabilities of Four Different Radiographic Grading Scales of Osteoarthritis of the Knee Joint. J Knee Surg. 2018;31(3):247-253.

16. Weidow J, Cederlund CG, Ranstam J, et al. Ahlbäck grading of osteoarthritis of the knee: poor reproducibility and validity based on visual inspection of the joint. Acta Orthop. 2006;77(2):262-266.

17. Lysholm J, Hamberg P, Gillquist J. The correlation between osteoarthrosis as seen on radiographs and on arthroscopy. Arthroscopy. 1987;3(3):161165 . 
18. Fife RS, Brandt KD, Braunstein EM, et al. Relationship between arthroscopic evidence of cartilage damage and radiographic evidence of joint space narrowing in early osteoarthritis of the knee. Arthritis Rheum. 1991;34(4):377-382.

19. Ayral X, Gueguen A, Ike RW, et al. Inter-observer reliability of the arthroscopic quantification of chondropathy of the knee. Osteoarthritis Cartilage. 1998;6(3):160-166.

20. Wada $\mathrm{M}$, Baba $\mathrm{H}$, Imura $\mathrm{S}$, et al. Relationship between radiographic classification and arthroscopic findings of articular cartilage lesions in osteoarthritis of the knee. Clin Exp Rheumatol. 1998;16(1):15-20.

21. Jerosch J, Castro WH, de Waal Malefijt MC, et al. Interobserver variation in diagnostic arthroscopy of the knee joint. "How really objective are arthroscopic findings?". Unfallchirurg. 1997;100(10):782-786.

22. Marx RG, Connor J, Lyman S, et al. Multirater agreement of arthroscopic grading of knee articular cartilage. Am J Sports Med. 2005;33(11):1654 1657.

23. Wright RW, Boyce RH, Michener T, et al. Radiographs are not useful in detecting arthroscopically confirmed mild chondral damage. Clin Orthop Relat Res. 2006;442:245-251.

24. AlOmran AS. Osteoarthritis of knee: correlation between radiographic and arthroscopic findings. Int Surg. 2009;94(3):269-272.

25. Lasmar NP, Lasmar RC, Vieira RB, et al. Assessment of the reproducibility of the outerbridge and FSA classifications for chondral lesions of the knee. Rev Bras Ortop. 2015;46(3):266-269.

26. Lakkireddy M, Bedarakota D, Vidyasagar J, et al. Correlation among Radiographic, Arthroscopic and Pain Criteria for the Diagnosis of Knee Osteoarthritis. J Clin Diagn Res. 2015;9(12):RC04-7.

27. Rosenberg TD, Paulos LE, Parker RD, et al. The forty-five-degree posteroanterior flexion weight-bearing radiograph of the knee. $J$ Bone Joint Surg Am. 1988;70(10):1479-1483.

28. Dervin GF, Feibel RJ, Rody K, et al. 3-Foot standing AP versus 45 degrees PA radiograph for osteoarthritis of the knee. Clin J Sport Med. 2001;11(1):10-16.

29. Kijowski R, Blankenbaker D, Stanton P, et al. Arthroscopic validation of radiographic grading scales of osteoarthritis of the tibiofemoral joint. AJR Am J Roentgenol. 2006;187(3):794-799.

30. Wright RW, Huston LJ, Spindler KP, et al. Descriptive epidemiology of the Multicenter ACL Revision Study (MARS) cohort. Am J Sports Med. 2010;38(10):1979-1986.
31. Duncan ST, Khazzam MS, Burnham JM, et al. Sensitivity of standing radiographs to detect knee arthritis: a systematic review of Level I studies. Arthroscopy. 2015;31(2):321-328.

32. Heng HY, Bin Abd Razak HR, Mitra AK. Radiographic grading of the patellofemoral joint is more accurate in skyline compared to lateral views. Ann Transl Med. 2015;3(18):263.

33. Outerbridge RE. The etiology of chondromalacia patellae. J Bone Joint Surg Br. 1961;43-B:752-757.

34. Niskanen RO, Paavilainen PJ, Jaakkola M, et al. Poor correlation of clinical signs with patellar cartilaginous changes. Arthroscopy. 2001;17(3):307-310.

35. Rodríguez-Merchán EC, Gómez-Cardero P. The outerbridge classification predicts the need for patellar resurfacing in TKA. Clin Orthop Relat Res. 2010;468(5):1254-1257.

36. Zha GC, Feng S, Chen XY, et al. Does the grading of chondromalacia patellae influence anterior knee pain following total knee arthroplasty without patellar resurfacing? Int Orthop. 2018;42(3):513-518.

37. Khan FA, Koff MF, Noiseux NO, et al. Effect of local alignment on compartmental patterns of knee osteoarthritis. J Bone Joint Surg Am. 2008;90(9):1961-1969.

38. Cameron ML, Briggs KK, Steadman JR. Reproducibility and reliability of the outerbridge classification for grading chondral lesions of the knee arthroscopically. Am J Sports Med. 2003;31(1):83-86.

39. Brismar BH, Wredmark T, Movin T, et al. Observer reliability in the arthroscopic classification of osteoarthritis of the knee. J Bone Joint Surg Br. 2002;84(1):42-47.

40. Bin Abd Razak HR, Heng HY, Cheng KY, et al. Correlation between radiographic and arthroscopic findings in Asian osteoarthritic knees. $J$ Orthop Surg (Hong Kong). 2014;22(2):155-157.

41. Spahn G, Klinger HM, Hofmann GO. How valid is the arthroscopic diagnosis of cartilage lesions? Results of an opinion survey among highly experienced arthroscopic surgeons. Arch Orthop Trauma Surg. 2009;129(8):1117-1121.

42. Kijowski R, Blankenbaker D, Stanton P, et al. Correlation between radiographic findings of osteoarthritis and arthroscopic findings of articular cartilage degeneration within the patellofemoral joint. Skeletal Radiol. 2006;35(12):895-902. 